\title{
First case of Perceval S prosthesis early structural valve deterioration: Not an easy reoperation
}

\author{
Ismail Bouhout, MD, MSc, Pierre-Emmanuel Noly, MD, MSc, Andres Parisi, MD, and
}

Denis Bouchard, MD, PhD, Montreal, Québec, Canada

\footnotetext{
From the Department of Cardiac Surgery, Montréal Heart Institute, Université de Montréal, Montreal, Québec, Canada.

I.B. and P-E.N. share co-first authorship.

Disclosures: D.B. reports proctorship fees from Sorin Canada. All other authors have nothing to disclose with regard to commercial support.

Received for publication Jan 8, 2016; revisions received March 31, 2016; accepted for publication May 4, 2016; available ahead of print June 4, 2016.

Address for reprints: Denis Bouchard, MD, PhD, Department of Cardiac Surgery, Montreal Heart Institute, 5000 rue Belanger, Montreal HIT1C8 (E-mail: andre.denis.bouchard@gmail.com).

J Thorac Cardiovasc Surg 2016;152:e71-3

$0022-5223 / \$ 36.00$

Copyright (c) 2016 by The American Association for Thoracic Surgery

http://dx.doi.org/10.1016/j.jtcvs.2016.05.013
}

A 54-year-old man presented with symptomatic isolated aortic stenosis (mean aortic gradient, $63 \mathrm{~mm} \mathrm{Hg}$; estimated aortic valve area, $1.1 \mathrm{~cm}^{2}$ ). The left ventricular function was normal. The patient's medical history included obesity, obstructive sleep apnea, chronic kidney failure (glomerular filtration rate, $45 \mathrm{~mL} / \mathrm{min}$ ), diabetes, dyslipidemia, and high blood pressure. The patient underwent an amputation of the left arm and left leg after a car trauma. Considering the high risk of sternal dehiscence associated with the patient's poor mobility, aortic valve replacement was performed via a small right thoracotomy. During the surgery, the exposure was difficult, which motivated the implantation of an extra-large sutureless Perceval S prosthesis (Sorin Group, Saluggia, Italy). The cardiopulmonary bypass and crossclamp times were 52 minutes and 43 minutes, respectively. The intraoperative transesophageal echocardiogram revealed a well-deployed prosthesis with symmetric cusps. There was no intravalvular or paravalvular leaks. The postoperative course was uneventful, and the patient was discharged on day 4 . The postoperative transthoracic echocardiogram showed a mean aortic gradient of $23 \mathrm{~mm} \mathrm{Hg}$ with no sign of paravalvular leak.

Two years later, the patient presented with a recurrence of severe dyspnea and was admitted for investigation. The transthoracic echocardiogram showed immobile leaflets

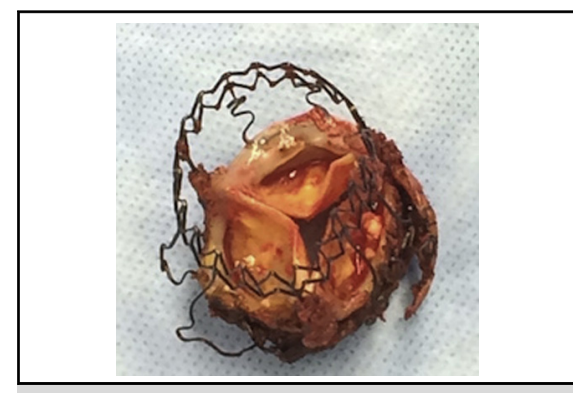

Explanted Perceval S prosthesis.

Central Message

This is the first case reported of early dysfunction of a Perceval S prosthesis (Sorin Group, Saluggia, Italy). Explantation of the Perceval $S$ prosthesis was difficult because the prosthesis stent was embedded in the aortic wall.

See Editorial Commentary page e73.

with a mean aortic gradient of $84 \mathrm{~mm} \mathrm{Hg}$ and no regurgitation (Figure 1). Blood cultures were negative. We decided on surgical replacement of the degenerated prosthesis, and a median sternotomy was performed. Only few adherences between the aorta and the right atrium were present. The previous aortotomy was reopened. Surgical examination of the prosthesis revealed stiffened leaflets with no tear and no thrombus (Figure 2). The prosthesis was tightly embedded in the aorta, especially the intra-annular prosthesis-sealing collar. Fifty-two minutes were required to remove the prosthesis while preserving the aortic root. Then a mechanical prosthesis was implanted. The cardiopulmonary bypass and crossclamp times were 135 minutes and 110 minutes, respectively. No

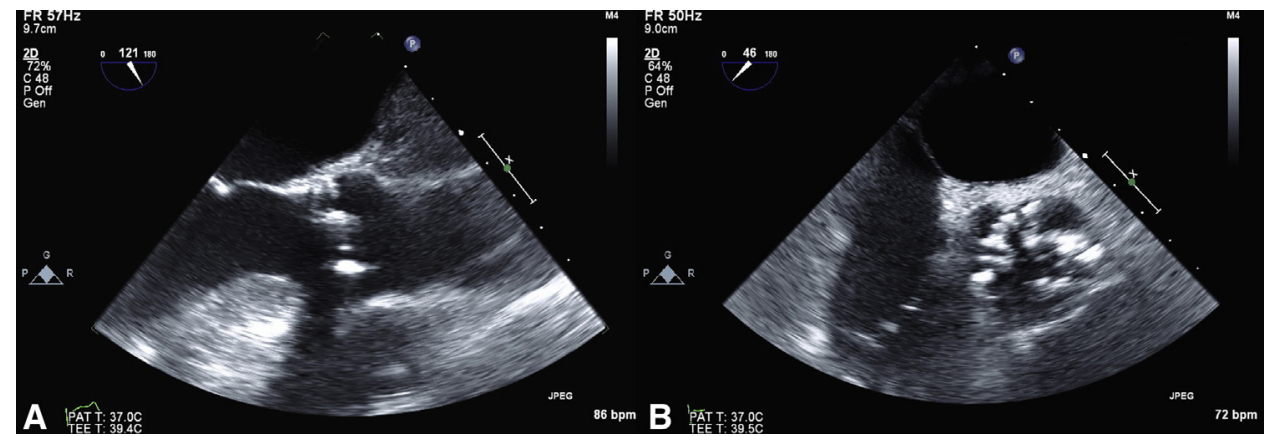

FIGURE 1. Intraoperative transesophageal echocardiography showing maximal opening of the prosthetic aortic valve. A, Long axis. B, Short axis. 

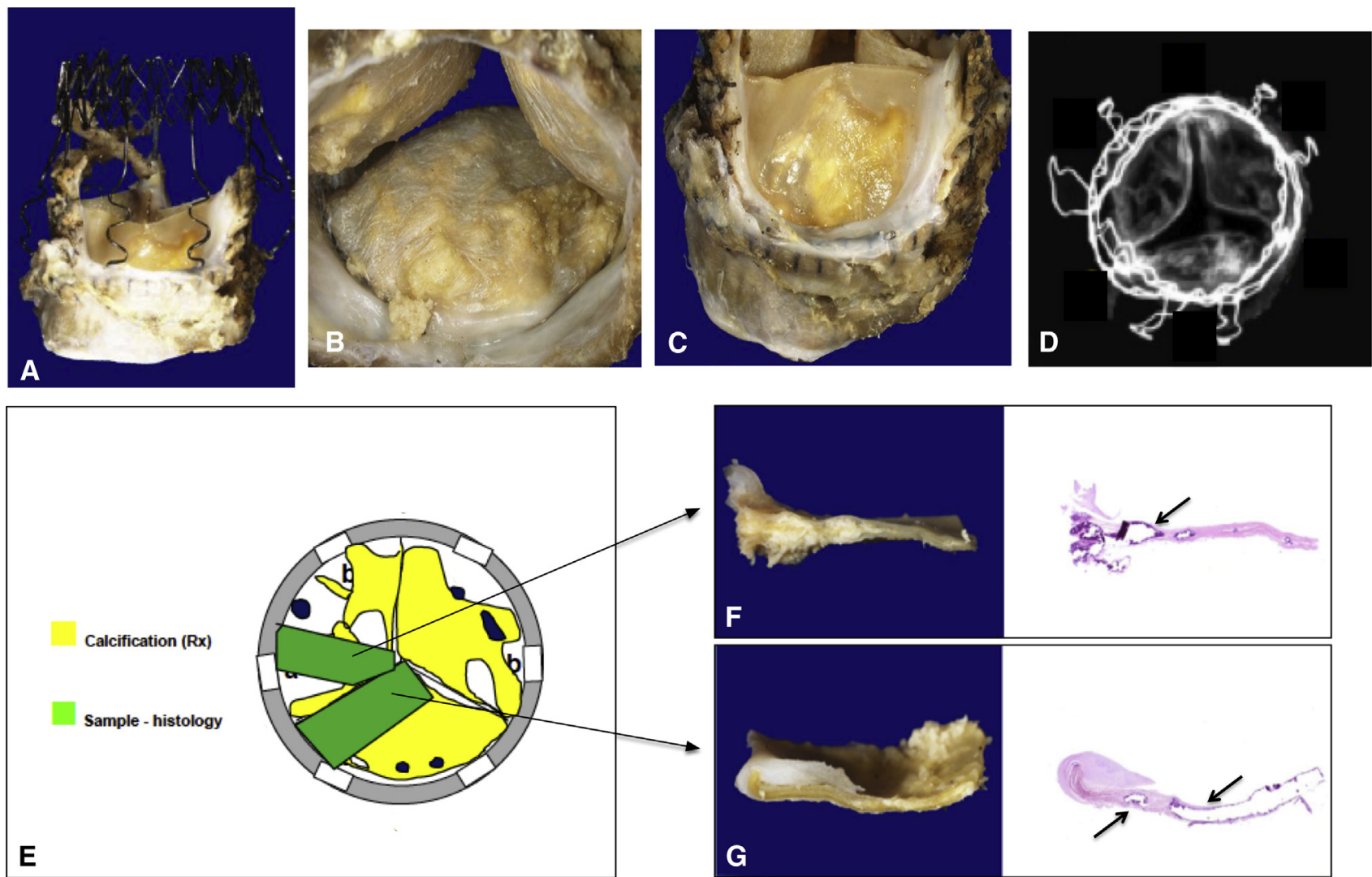

FIGURE 2. Macroscopic examination of the explanted Perceval S prosthesis (Sorin Group, Saluggia, Italy) (A) revealed severe calcifications on both sides of all leaflets as shown in the inflow (B) and outflow (C) views. X-rays of the prosthesis also showed large intrinsic calcifications in all leaflets (D). Schematic view of the structural deterioration of the prosthesis $(\mathrm{E})$. Histologic study $(\mathrm{F}$ and $\mathrm{G})$ revealed thick free edges due to fibrous pannus and large intrinsic calcifications (black arrows). Rx, X-ray.

conduction disorder occurred, and the postoperative course was uneventful. The prosthesis bacteriologic cultures were all negative. Pathologic study showed stiffened leaflets due to intrinsic and vegetating calcifications (Figures 2 and 3). Fibrous pannus depositions were visible in the skirt, all struts, and along almost all adherent margins.

\section{DISCUSSION}

The sutureless aortic prosthesis is a new and promising alternative to the standard sutured aortic substitutes. The mean advantages of the sutureless aortic prosthesis are to shorten the cardiopulmonary bypass time, thus potentially decreasing postoperative mortality and morbidity in high-risk patients. In addition, theses prostheses facilitate minimally invasive approaches. ${ }^{1}$ To our knowledge, no case of early Perceval $\mathrm{S}$ structural valve deterioration (SVD) has been reported since its first implantation in 2008. Our experience with this prosthesis started in 2011, and this is the unique case of SVD we observed in more than 340 implanted Perceval prostheses. ${ }^{2}$

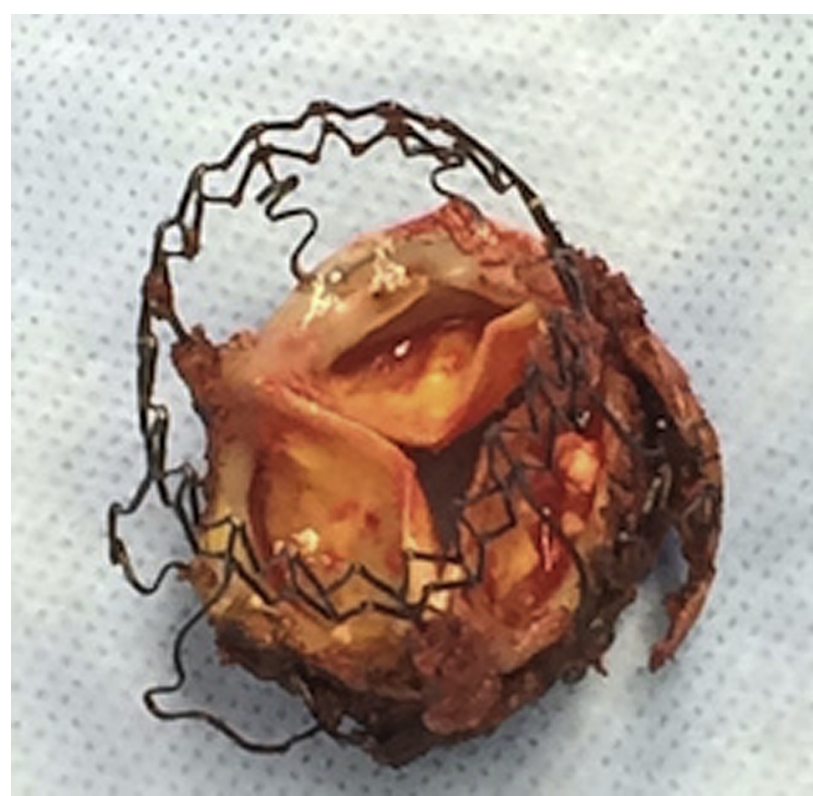

FIGURE 3. Explanted Perceval S prosthesis. 
The Perceval $\mathrm{S}$ is a bovine pericardial valve with a selfexpendable nitinol frame. The design of this prosthesis closely resembles that of the Freedom Solo (Sorin Group) stentless prosthesis that was associated with a higher incidence of SVD at 5 years. ${ }^{3}$ However, in this case, the patient's age and history of chronic kidney failure are 2 major risk factors that could explain the early SVD observed. ${ }^{4}$ Thus, this report of early Perceval degeneration should be taken with caution.

\section{CONCLUSIONS}

Previously published case reports on the CoreValve (Medtronic, Inc, Minneapolis, Minn) prosthesis removal described an easy explantation with proper aortic wall endarterectomy. ${ }^{5}$ As a result of the Perceval S prosthesis design, we first thought that the removal would be easily performed. In this case, the prosthesis stent was covered by neoendothelialization and included in the aortic wall.
The hardest part to free was the sealing collar that was imbedded in the aortic annulus. Half of the crossclamp time was dedicated to the prosthesis removal because of a careful and meticulous cautery dissection of the prosthesis collar to avoid damaging the aortic annulus and the need for aortic root replacement.

\section{References}

1. Zannis K, Folliguet T, Laborde F. New sutureless aortic valve prosthesis: another tool in less invasive aortic valve replacement. Curr Opin Cardiol. 2012;27:125-9.

2. Mazine A, Teoh K, Bouhout I, Bhatnagar G, Pelletier M, Voisine P, et al Sutureless aortic valve replacement: a Canadian multicentre study. Can J Cardiol. 2015;31:63-8.

3. Stanger O, Bleuel I, Gisler F, Gober V, Reineke S, Gahl B, et al. The Freedom Solo pericardial stentless valve: single-center experience, outcomes, and long-term durability. J Thorac Cardiovasc Surg. 2015;150:70-7.

4. Forcillo J, Pellerin M, Perrault LP, Cartier R, Bouchard D, Demers P, et al Carpentier-Edwards pericardial valve in the aortic position: 25-years experience. Ann Thorac Surg. 2013;96:486-93.

5. Wang LW, Granger EK, McCourt JA, Pye R, Kaplan JM, Muller DW. Late surgical explantation and aortic valve replacement after transcatheter aortic valve implantation. Ann Thorac Surg. 2015;99:1434-6.

\title{
EDITORIAL COMMENTARY
}

\section{The potential emerging truth about balanced sacrifices in surgery}

\author{
Fraser D. Rubens, MD, MSc, FACS, FRCSC
}

From the Division of Cardiac Surgery, University of Ottawa Heart Institute, Ottawa, Ontario, Canada. Disclosures: Author has nothing to disclose with regard to commercial support.

Received for publication May 7, 2016; accepted for publication May 9, 2016; available ahead of print June 24, 2016.

Address for reprints: Fraser D. Rubens, MD, MSc, FACS, FRCSC, University of Ottawa Heart Institute, 40 Ruskin

St, Ottawa, Ontario K1Y 4W7 (E-mail: frubens@ottawaheart.ca).

J Thorac Cardiovasc Surg 2016;152:e73-4

$0022-5223 / \$ 36.00$

Copyright (C 2016 by The American Association for Thoracic Surgery

http://dx.doi.org/10.1016/j.jtcvs.2016.05.029

When I was a trainee, much of our academic discussion regarding valve choice centered on long-term results. Durability was paramount, and surgical teams were loath to make the most minute changes that could possibly jeopardize those outcomes. ("What? You changed the color of the valve holder?") We recognized the commitment that performing a maximally invasive series of interventions, such as a sternotomy, cardiopulmonary bypass, and opening a cardiac chamber, entailed that what we put in had better last the duration. With this approach, despite the aging of our clientele, outcome results were getting better and better.

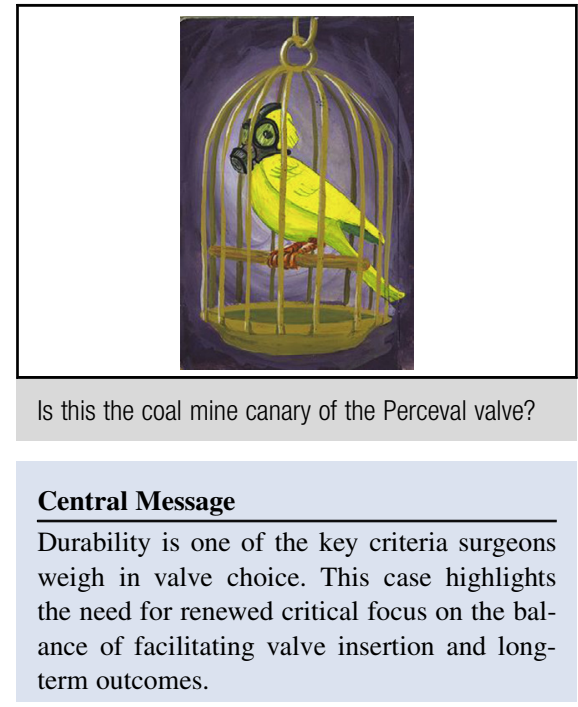

See Article page e71. 